\title{
Comment on "Association of mean platelet volume with echocardiographic findings in patients with severe rheumatic mitral stenosis"
}

\author{
Erkan Coban ${ }^{*}$ (D) \\ Akdeniz University, Faculty of Medicine, Department of Internal Medicine, Antalya, Turkey
}

Received: 9 August 2019; Accepted: 26 August 2019; epublished: 4 November 2019

I have read with great interest the recently published article by Aslanabadi et al. ${ }^{1}$ Authors reported that patients with rheumatic mitral stenosis has a higher mean platelet volume (MPV) compared to the healthy individuals. However, there are major limitations about MPV levels in this study;

1) In this study, MPV measurement technique is not written. The MPV is dependent on a number of variables, including time of analysis after venepuncture, method of analysis, anticoagulant used and specimen storage temperature. Pre-analytical variables, such as the anticoagulant used, and the time between blood collection and measurement are known to significantly affect MPV measurements. Although EDTA is traditionally used and recommended for samples destined for blood counting it is well known that platelets collected into EDTA anticoagulants undergo time-dependent platelet swelling and activation. ${ }^{2-4}$ The nature of the study leads to a significant problem because the MPV results could not be standardized. Therefore, MPV-based evaluation may give erroneous results.
Competing interests

None.

Ethical approval

Not applicable.

References

1. Aslanabadi N, Separham A, Valae Hiagh L, Karkon Shayan F, Toufan M, Ghaffari S, et al. Association of mean platelet volume with echocardiographic findings in patients with severe rheumatic mitral stenosis. J Cardiovasc Thorac Res 2019;11(2):95-99. doi: 10.15171/jcvtr.2019.17.

2. Jackson SR, Carter JM. Platelet volume: laboratory measurement and clinical application. Blood Rev 1993;7(2):104-113.

3. Harrison P, Goodall AH. Studies on mean platelet volume (MPV) - New Editorial Policy. Platelets 2016;27(7):605-6. doi: 10.1080/09537104.2016.1225467.

4. Beyan C, Beyan E. Were the measurements standardized sufficiently in published studies about mean platelet volume? Blood Coagul Fibrinolysis 2017;28:234-236. doi: 10.1097/MBC.0000000000000586.

\footnotetext{
*Corresponding Author: Erkan Coban, Email: drecco68@gmail.com

(c) 2019 The Author (s). This is an open access article distributed under the terms of the Creative Commons Attribution License (http://creativecommons. org/licenses/by/4.0), which permits unrestricted use, distribution, and reproduction in any medium, provided the original work is properly cited.
} 